\title{
Arctic low-level boundary layer clouds: in situ measurements and simulations of mono- and bimodal supercooled droplet size distributions at the top layer of liquid phase clouds
}

\author{
M. Klingebiel ${ }^{1}$, A. de Lozar $^{2}$, S. Molleker ${ }^{3}$, R. Weigel ${ }^{1}$, A. Roth $^{3}$, L. Schmidt ${ }^{4}$, J. Meyer ${ }^{5,6}$, A. Ehrlich ${ }^{7}$, R. Neuber ${ }^{4}$, \\ M. Wendisch ${ }^{7}$, and S. Borrmann ${ }^{1,3}$ \\ ${ }^{1}$ Institute for Physics of the Atmosphere, University of Mainz, Mainz, Germany \\ ${ }^{2}$ Max Planck Institute for Meteorology, Hamburg, Germany \\ ${ }^{3}$ Max Planck Institute for Chemistry, Mainz, Germany \\ ${ }^{4}$ Alfred Wegener Institute for Polar and Marine Research, Potsdam, Germany \\ ${ }^{5}$ Institute of Energy and Climate Research (IEK-7), Forschungszentrum Jülich, Jülich, Germany \\ ${ }^{6}$ Institute of Energy \& Environmental Technology e.V. (IUTA), Duisburg, Germany \\ ${ }^{7}$ Leipzig Institute for Meteorology, University of Leipzig, Leipzig, Germany
}

Correspondence to: M. Klingebiel (klingebi@uni-mainz.de)

Received: 15 April 2014 - Published in Atmos. Chem. Phys. Discuss.: 5 June 2014

Revised: 30 September 2014 - Accepted: 12 November 2014 - Published: 16 January 2015

\begin{abstract}
Aircraft borne optical in situ size distribution measurements were performed within Arctic boundary layer clouds with a special emphasis on the cloud top layer during the VERtical Distribution of Ice in Arctic clouds (VERDI) campaign in April and May 2012. An instrumented Basler BT-67 research aircraft operated out of Inuvik over the Mackenzie River delta and the Beaufort Sea in the Northwest Territories of Canada. Besides the cloud particle and hydrometeor size spectrometers the aircraft was equipped with instrumentation for aerosol, radiation and other parameters. Inside the cloud, droplet size distributions with monomodal shapes were observed for predominantly liquid-phase Arctic stratocumulus. With increasing altitude inside the cloud the droplet mean diameters grew from 10 to $20 \mu \mathrm{m}$. In the upper transition zone (i.e., adjacent to the cloud-free air aloft) changes from monomodal to bimodal droplet size distributions (Mode 1 with $20 \mu \mathrm{m}$ and Mode 2 with $10 \mu \mathrm{m}$ diameter) were observed. It is shown that droplets of both modes coexist in the same (small) air volume and the bimodal shape of the measured size distributions cannot be explained as an observational artifact caused by accumulating data point populations from different air volumes. The formation of the second size mode can be explained by (a) entrainment and activation/condensation of fresh aerosol particles, or (b) by dif-
\end{abstract}

ferential evaporation processes occurring with cloud droplets engulfed in different eddies. Activation of entrained particles seemed a viable possibility as a layer of dry Arctic enhanced background aerosol (which was detected directly above the stratus cloud) might form a second mode of small cloud droplets. However, theoretical considerations and model calculations (adopting direct numerical simulation, DNS) revealed that, instead, turbulent mixing and evaporation of larger droplets are the most likely reasons for the formation of the second droplet size mode in the uppermost region of the clouds.

\section{Introduction}

The Arctic sea ice plays an important role in the global climate system as it partly insulates the Arctic Ocean especially in the winter season and diminishes the exchange of heat, momentum and gases between ocean and atmosphere (Lemke et al., 2007). Surface temperature analyses show the strongest temperature increase in the Arctic region in the past decades between 1961-1971 and 2003-2013 as resulting from the GISS database (Hansen et al., 2010). This temperature rise drives a melting process of Arctic sea ice which 
reduces the albedo and, thus, increases absorption of solar radiation at the sea surface, with the consequence of even more enhanced ice melting. This so-called "direct albedo feedback" occurs in the Arctic summer and is a self-amplifying melting effect. As a result the temperature of the upper mixing layer of the Arctic Ocean is increasing. Most of the heat stored during summer in the mixing layer is released in winter leading to an indirect albedo feedback causing Arctic amplification of near-air surface temperature (Wendisch et al., 2013). In the Arctic satellite measurements (CALIPSO and ICESat) between 2003 and 2008 it is shown that cloud cover and optical depth reach a maximum over ice-free waters (Palm et al., 2010). The authors also conclude that the higher optical depths are caused by geometrically thicker low level clouds over the water. In addition an increasing trend of cloud coverage between 7 and $10 \%$ over a period of five years was observed from the satellite data, which is most likely as result of decreasing sea ice coverage (Palm et al., 2010). Several publications indicate that Arctic clouds might have been an important factor in explaining the recent dramatic Arctic sea ice losses (Kay et al., 2008; Perovich et al., 2008; Schweiger and Lindsay, 2008). The microphysical characteristics of clouds, e.g., particle phase, size, number concentration, and shape determine the radiative properties which influence the atmospheric radiation budget (Curry et al., 1996; Ehrlich et al., 2008a). At the same time, climate simulations indicate that the sea salt emissions may increase with receding ice coverage leading to increasing values of optical depths of the natural background aerosol particles. This implies a negative direct climate forcing of -0.2 to $-0.4 \mathrm{~W} \mathrm{~m}^{-2}$ (Struthers et al., 2011). Such estimates are still highly uncertain partly because of the crude representation of Arctic clouds and aerosol-cloud interactions in the many models (Struthers et al., 2011). Especially mixed-phase low level clouds are of major concern here. Phase-dependent microphysical processes such as collision, coalescence, aggregation, riming and secondary ice formation (e.g., HallettMossop ice multiplication) determine the growth and shape of the ice particles in mixed-phase Arctic clouds (Pruppacher and Klett, 2010). Nucleation, growth, and sedimentation processes of ice crystals are still not comprehensively understood which leads to discrepancies between observed and modeled ice number concentrations (Fan et al., 2009; Morrison et al., 2008; Avramov et al., 2011).

For the development process of clouds aerosol particles may play a significant role as they provide cloud condensation nuclei $(\mathrm{CCN})$ and influence the direct and indirect cloud radiative effects (Lemke et al., 2007). Several previous measurements indicate a correlation between the number concentrations of aerosol and of cloud particles which implies an effect of aerosol particles on the cloud particle size distribution (SD) (Pruppacher and Klett, 2010). Aerosol particles may also influence the lifetime of clouds which form at the bottom of stable boundary layers (Stevens, 2005). These boundary layer clouds act to cool the atmosphere (annually and globally averaged) which is explained by the dominance of the solar albedo effect or the emission of thermal-infrared radiation. However Arctic boundary layer clouds lead to a net warming effect of the below-cloud atmosphere depending on the season. This is due to the generally low sun elevation, the long-lasting polar night, and the high solar surface albedo of land/sea ice and snow (Wendisch et al., 2013; Shupe and Intieri, 2004). Moreover, the magnitude of the radiative forcing of boundary-layer, mixed-phase Arctic clouds critically depends on the clouds' macroscopic and microscopic properties. Therefore, in situ measurements are necessary to study aerosol-cloud interactions and their radiative effects (Lawson et al., 2001; Lihavainen et al., 2010).

With regard to the cloud radiative effects, the upper top layer of boundary layer clouds is very important because it dominates the overall cloud radiative properties (Ehrlich et al., 2009) and thus is a key for the Arctic radiation balance (Stevens, 2005). Platnick (2000) showed that for inhomogeneous liquid water clouds the vertical weighting function of the reflected radiation has a maximum close below the cloud top. For mixed-phase clouds Ehrlich et al. (2009) showed that a small fraction of ice crystals in the cloud top layer may change the cloud top reflectivity significantly with possible consequences for the accuracy of cloud remote sensing. Therefore, microphysical processes at cloud top, such as the cloud top entrainment, are another critical issue which still needs proper representation in the numerical models. Cloud top entrainment is driven by the evaporation inducing downward-directed turbulent motion which then entrains the cloud - free air from above. And this is crucial for the lifetime of the entire cloud as well as the radiative budget because the entrainment and its rates influence directly droplet size and thus reflectivity in the visible. The main sources that produce turbulent energy at the cloud top are radiative cooling and evaporative cooling (Pettersen 1938; Siems and Bretherton, 1992).

In the past 20 years several aircraft campaigns were conducted to study the properties of arctic clouds:

- In April 2008, during the International Polar Year, the NASA Arctic Research of the Composition of the Troposphere from Aircraft and Satellites (ARCTAS) mission was conducted to better understand the changes in Arctic atmospheric chemical composition and climate (Jacob et al., 2010).

- At the same time, the Indirect and Semi-Direct Aerosol Campaign (ISDAC) was performed by using 41 instruments on the NRC Convair-580 aircraft. With this measurement platform the most complete data set on arctic boundary layer and cirrus microphysical properties was collected over the north slope of Alaska (McFarquhar et al., 2011).

- One year earlier, the Arctic STudy of Aerosol, clouds and Radiation (ASTAR 2007) campaign was performed 
to characterize microphysical and optical properties of Arctic clouds. The thermodynamic phase of the detected clouds was estimated by measurements of the reflected solar radiation. Three different methods were used to identify the ice phase in Arctic boundary layer clouds (Ehrlich et al., 2008b).

- In 2004, the Mixed-Phase Arctic Cloud Experiment (M-PACE) was conducted to study the microphysical structure of Arctic mixed-phase clouds (Verlinde et al., 2007).

- Two earlier campaigns were the Surface HEat Budget of the Arctic (SHEBA) (Perovich et al., 2000), and the

- First ISCCP (International Satellite Cloud Climatology Project) Regional Experiment Arctic Clouds Experiment (FIRE ACE) (Curry et al., 1999). The SHEBA campaign was conducted 1997-1998 to study the heat transfer processes between the ice covered Arctic Ocean and the atmosphere. At the same time, in April-July 1998, the FIRE ACE campaign was performed to improve (a) the satellite retrieval of cloud and surface characteristics in the Arctic, and (b) the representation of Arctic clouds and radiation in general circulation models. For this purpose, four aircraft were equipped with instrumentation as described in Curry et al. (1999).

During FIRE ACE, cloud particle SDs of Arctic boundary layer clouds were studied. Monomodal SDs were mostly observed under adiabatic and homogeneous liquid water cloud conditions whereas bimodal SDs appeared near the cloud top, when the temperature and liquid water content profiles indicated non-adiabatic and inhomogeneous cloud conditions (Lawson et al., 2001). Mixed-phase clouds, which consist of liquid and ice phase particles, appear mainly in the autumn and springtime. Boundary layer clouds containing ice and liquid water were typically detected in May in an altitude range from 150 to $1200 \mathrm{~m}$ (Lawson et al., 2001). The detected ice particles had diameters between $8 \mu \mathrm{m}$ and $1 \mathrm{~mm}$ while liquid cloud droplets mostly are in a size range of tens of micrometers with maximum droplet number concentrations of $500 \mathrm{~cm}^{-3}$ (Curry et al., 1996).

The purpose of this study is to analyze in further detail the microphysical properties inside and at the top of the boundary layer stratus clouds in the Beaufort Sea area with emphasis on the occurrence of monomodal and bimodal distributions and the connection to turbulent mixing processes at the cloud top levels.

\section{Field campaign and instrumentation}

Airborne microphysical measurements within Arctic boundary layer's mixed-phase clouds were performed during the VERtical Distribution of Ice in Arctic clouds (VERDI) field campaign. The POLAR 5 research aircraft (Basler BT-67, modification of a DC-3), operated by the Alfred Wegener Institute (AWI, Helmholtz Centre for Polar and Marine Research, Bremerhaven, Germany), was equipped with instruments to carry out in situ measurements aimed in particular at mixed-phase clouds, during the Arctic spring season. For the detection of cloud particles, a Cloud Combination Probe (CCP), a Small Ice Detector (SID), a Novel Ice eXperiment - Cloud and Aerosol Particle Spectrometer (NIXE-CAPS), a Cloud and Aerosol Spectrometer with DEPOLarization (CAS-DPOL), and a Precipitation Imaging Probe (PIP) were used. With these instruments it is possible to cover a diameter size range from $0.6 \mu \mathrm{m}$ up to $6.4 \mathrm{~mm}$. Four of the cloud particle spectrometers with partially overlapping detection size ranges were simultaneously operated side by side to provide independent SD measurements. Solar (spectral and broadband) as well as broadband thermal-infrared radiation sensors and an aerosol Optical Particle Counter (SkyOPC) were deployed on the aircraft. Also, a cloud-aerosol lidar, and meteorological instruments were part of the instrumentation. With this equipment, different situations of ice-, liquid-phase and mixed-phase clouds were probed. VERDI was performed from 25 April to 17 May 2012 out of Inuvik, Canadian Northwest Territories, with the main operation area over the Mackenzie River delta and the Beaufort Sea. The measurements in this study are mainly based on the CCP, the Sky-OPC and the lidar instrument. The CCP integrates two instruments to measure parameters of individual cloud hydrometeors (Wendisch and Brenquier, 2013) and was a modified version of the instrument initially manufactured by Droplet Measurement Technologies (DMT, Boulder, CO, USA, see http://dropletmeasurement.com/). It consists of a Cloud Droplet Probe (CDP) and a Cloud Imaging Probe (CIP grey scale - denoted as CIPgs in the following) which in combination cover a size diameter range from 2 to $960 \mu \mathrm{m}$, including large aerosol particles, liquid cloud droplets and small frozen hydrometeors. The technique of the CDP is based on forward light-scattering with a light collection angle from $4^{\circ}$ up to $12^{\circ}$, similar to the Forward Scattering Spectrometer Probe (FSSP). A laser diode wavelength of $658 \mathrm{~nm}$ is used as light source. The CDP instrument measures particles in a diameter size region between 2 and $50 \mu \mathrm{m}$ with a size resolution provided by 30 detector channels. Its general performance and the sample area were tested and measured using a piezoelectric droplet generator laboratory setup similar to the design of Lance et al. (2010). As a result a sampling area of $0.27 \pm 0.025 \mathrm{~mm}^{2}$ was obtained. Measurements of cloud probes are often being affected by shattering (Jensen et al., 2009; Korolev et al., 2011). However, this CDP is an open path design and is equipped with tips of particular shape to minimize the impact of shattering on the measurement (Korolev et al., 2013). Furthermore, the instrument records the particle-by-particle $(\mathrm{PbP})$ data which allows for excluding collection periods potentially affected by shattering (Field et al., 2003, 2006). The CIPgs instrument, the second sub-instrument of the CCP, records two- 
dimensional shadow images of cloud particles in a size range from 15 up to $960 \mu \mathrm{m}$ with an optical resolution of $15 \mu \mathrm{m}$. Specialized algorithms are used to process and analyze the captured images in order to estimate particle number concentrations, particle SDs, and to differentiate particle shapes (Korolev, 2007).

The Sky-OPC is a Series 1.129 aerosol spectrometer manufactured by Grimm Aerosol Technik GmbH (see http:// www.grimm-aerosol.com/en/), which determines the aerosol particle number concentrations within 31 size channels and the particle sizes from $250 \mathrm{~nm}$ up to $32 \mu \mathrm{m}$. However, due to the sampling inlet efficiency of the applied (solid diffuser) aerosol inlet (Huebert et al., 2004) for the POLAR 5, only aerosol particles of up to $1 \mu \mathrm{m}$ in diameter are representatively sampled from the ambient air. Individual particles are detected by their light scattering signal within an angular range from $60^{\circ}$ to $120^{\circ}$ of a diode-laser with a wavelength of $655 \mathrm{~nm}$. The geometry of the instrument is less sensitive to the refractive index than a narrow-cone forward scattering instrument. Nevertheless, because an inlet with a tube system inside the aircraft is used, the detected aerosol at the instrument is much drier than outside the aircraft. The sampling was such that particles were heated to temperatures more than $20^{\circ} \mathrm{C}$ above ambient before the size measurement of the OPC. The standard integration time of the Sky-OPC for one $\mathrm{SD}$ has been set to $6 \mathrm{~s}$ for the VERDI flights. Particle SDs recorded by several in situ instruments show a good agreement in the overlapping size ranges between 250 and $6.4 \mathrm{~mm}$.

The Airborne Mobile Aerosol Lidar (AMALi) emits laser pulses into the atmosphere and measures backscatter from air molecules and aerosols at the wavelengths 532 and $355 \mathrm{~nm}$, as well as depolarization at $532 \mathrm{~nm}$. Here the measurement at $532 \mathrm{~nm}$ is used to characterize the spatial structure of aerosol and cloud layers. During VERDI AMALi was operated in nadir pointing mode with a vertical resolution of up to $7.5 \mathrm{~m}$ and a maximum temporal resolution of $1 \mathrm{~s}$.

To identify the liquid phases during the campaign we used the NIXE-CAPS instrument which is able to discriminate between spherical and aspherical particles based on measurements of the polarization of laser light scattered by single particles. With this instrument it is possible to identify glaciated hydrometeors within the size range from 0.6 to $950 \mu \mathrm{m}$.

\section{Observations}

\subsection{Features inside the Arctic boundary layer clouds}

During VERDI, thirteen measurement flights were performed around Inuvik and above the Beaufort Sea, which was partly covered with ice. The probed supercooled liquid water clouds which are the subject of this study were primarily observed after 8 May 2012. Before that time only mixed- phase clouds, occasionally including glaciated hydrometeors as large as $6 \mathrm{~mm}$, were encountered during the observations.

The flight path of Flight 11 on 15 May 2012, is shown in Fig. 1, where a cloud layer was observed between $69.8^{\circ}$ and $70.5^{\circ}$ latitude (marked by the red line) in an altitude interval between 630 and $1060 \mathrm{~m}$ a.s.l. Figure 2 shows profiles of different meteorological and microphysical parameters of this cloud. The cloud top as marked by the dashed line was at an altitude of $990 \mathrm{~m}$. The profile was measured during a vertical ascent though the cloud layer. The layer directly above the dashed line (from 990 to $1060 \mathrm{~m}$ ) is denoted as the transition zone in the following. Here the temperature $T$ increased rapidly from 268 to $271 \mathrm{~K}$. The relative humidity $\mathrm{RH}$ inside the cloud was around $100 \%$ and above the cloud top RH declined to values around $80 \%$. Thus, the cloud is capped by a layer of warmer and drier air which is typical for the Arctic stratocumulus. The droplet number concentration, $N$, measured by the CDP, reveals constant values around $70 \mathrm{~cm}^{-3}$ almost independently of height. The liquid water content, LWC (as derived from the measured droplet SDs), increased with altitude inside the cloud. Both, constant $N$ and LWC increasing concurrently as function of height have been found to be typical for liquid water clouds generated by adiabatic lifting/cooling (McFarquhar et al., 2007). The calculated adiabatic LWC is indicated by the dash-dotted line in Fig. 2. While the measured and calculated LWCs are fairly close within the lowest $90 \mathrm{~m}$ of the cloud the influence of the entrainment processes becomes increasingly evident from the deviations between the two in the upper regions of the cloud. McFarquhar et al. (2011) showed similar trends in vertical profiles and in combination with radar measurements. Their results indicate vertical mixing driven by dynamics or turbulence.

To further characterize the atmospheric stability inside the cloud, the liquid water potential temperature $\theta_{1}$ (according to Stevens, 2005) is calculated. $\theta_{1}$ represents the potential temperature attained by evaporating all the liquid water in an air parcel through reversible wet adiabatic descent (Betts, 1973) and is defined as:

$\theta_{1} \approx \theta \exp \left(\frac{-\mathrm{LWC} L_{\mathrm{v}}}{c_{p} T}\right)$.

Here $\theta$ represents the potential temperature for dry air in Kelvin, LWC [in $\mathrm{kg} \mathrm{m}^{-3}$ ] is the mass of liquid water, while the latent heat of vaporization is denoted as $L_{\mathrm{v}}$ [in $\left.\mathrm{J} \mathrm{kg}^{-1} \mathrm{~K}^{-1}\right]$, the heat capacity as $c_{p}\left[\right.$ in $\left.\mathrm{J} \mathrm{kg}^{-1} \mathrm{~K}^{-1}\right]$ and the temperature as $T$. In Fig. 2 the liquid water potential temperature $\theta_{1}$ exhibits a continuous increase with altitude, which clearly indicates stable atmospheric conditions inside the cloud.

In the following, the microphysical measurements from Flight 11 on 15 May are described in detail for the layer inside the cloud (from 630 to $990 \mathrm{~m}$ ) and in the transition zone (990-1060 m) directly above. 


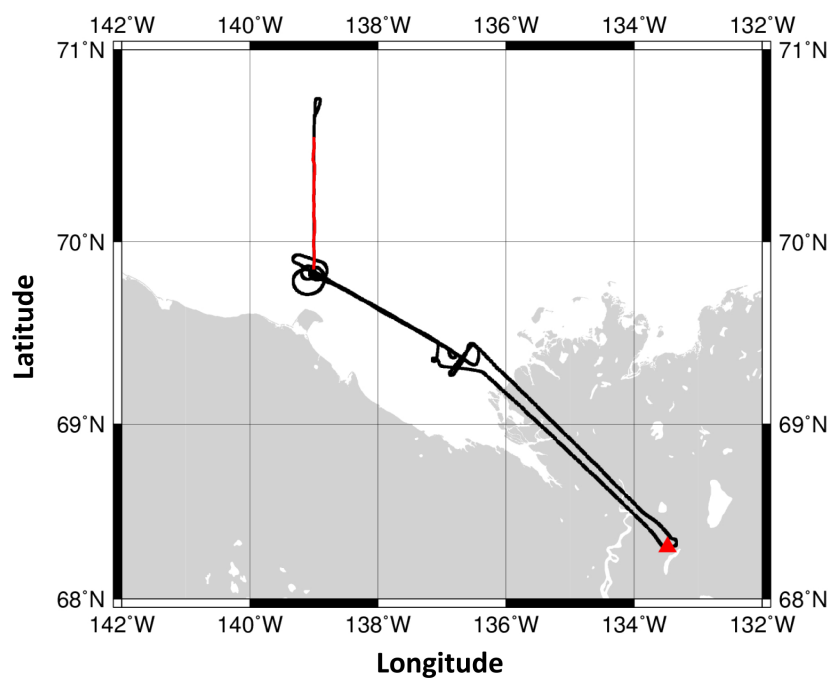

Figure 1. Track of Flight 11 as performed on 15 May 2012 in the Northwest Territories of Canada and the Beaufort Sea. The triangle marks Inuvik Mike Zubko Airport and the red line shows the region where the boundary layer cloud was penetrated.

The cloud consisted of supercooled liquid water droplets in a size range up to $50 \mu \mathrm{m}$. Only a few ice particles, mostly needles, with a number concentration of $0.75 \mathrm{~L}^{-1}$, were occasionally detected by the CIPgs instrument between altitudes of 630 to $990 \mathrm{~m}$. Figure 3 shows a time series of the aerosol number concentration (Fig. 3a) and the droplet geometric mean diameter (Fig. 3b). The altitude profile shown in Fig. $3 a$ and $b$ was flown with a heading to the north which is also marked by the red line in Fig. 1. Inside the cloud and during ascent between 20:08 and 20:22 UTC the droplet geometric mean diameter increased with altitude while the aerosol number concentration decreased.

The increasing size of the cloud droplets is also obvious in Fig. 4a-c where the narrow and monomodal SDs from different altitudes are displayed. The modal droplet diameter grows continuously from 12 to $20 \mu \mathrm{m}$ with altitude. Calculations for diffusional droplet growth, which are based on the set of four differential equations given in Pruppacher and Klett (2010) including released latent heat conduction to the air and back to the droplets, provide the necessary time for the droplets to grow from 12 to $20 \mu \mathrm{m}$ under the given ambient conditions. Assuming values for the relative humidity of $100.15,100.10$, and $100.08 \%$ the calculations indicate growth times of 7, 15 and $37 \mathrm{~min}$, respectively, which is well within the range of lifetimes for such clouds or cloud fragments. Under the assumption that the vertical updraft is $1 \mathrm{~m} \mathrm{~s}^{-1}$ the cloud particles would ascend 420, 600 and $2220 \mathrm{~m}$, respectively. However, the cloud depth that was studied is $360 \mathrm{~m}$ (altitude range: $630-990 \mathrm{~m}$ ), which is smaller than the calculated ascents. For the studied case, this implies that the vertical updrafts have to be smaller than
$1 \mathrm{~m} \mathrm{~s}^{-1}$ or circulation effects like those described in Korolev and Field (2008) must occur to maintain the cloud depth.

The monomodal shape of the SDs and the monotonic increase of their modal peak is comparable with observations by Lawson et al. (2001), who explained their appearance by adiabatic ascent of in-cloud air.

As shown in Fig. 2, deviations between the measurements and the expected adiabatic LWC due to an adiabatic ascent are obvious and indicate that the in-cloud air does not experience fully adiabatic conditions in our case. Continuous ascent throughout a certain altitude range implies averaging over an extended section of the linear flight path inside the cloud. This may have contributed to the deviations as it differs from a real vertical profile above one specific location.

Inside the transition zone at the cloud top, bimodal SDs with a second mode around $10 \mu \mathrm{m}$ are observed, as shown in Fig. 5c. This phenomenon was encountered only in the transition zone of the cloud during three VERDI flights (Flight 9 on 10 May, Flight 11 on 15 May and Flight 13 on 17 May). For the other flights in liquid water clouds only an increase of the droplet size diameter with altitude was found. The reason why during these flights no bimodal SDs were detected in the transition zone can be explained by the actual flight profile, which the aircraft conducted. The bimodal SDs only were observable (1) when the aircraft spent at least $1 \mathrm{~s}(\sim 70 \mathrm{~m})$ in the transition zone, or (2) when the plane slowly enough approached the top either from below inside the cloud or by entering the cloud descending from above. Often the aircraft crossed the relevant highest cloud level too fast for the acquisition of a SD with good counting statistics in each mode.

The SD shown in Fig. 5b was detected inside the cloud at an altitude of $1004 \mathrm{~m}$ and shows a monomodal shape similar to Fig. 4. To distinguish both modes, in the following the mode at larger sizes $(20 \mu \mathrm{m})$ will be labeled as Mode 1 and the one at smaller sizes is denoted as Mode 2. Figure 5a indicates that during Flight 11 several flight sequences with bimodal SDs were detected between 20:22:00 and 20:27:00 UTC when the aircraft flew through the transition zone of the cloud.

Besides the cloud droplets, also aerosol particles were measured during the VERDI campaign by using the SkyOPC and AMALi. Figure 6 provides two examples of AMALi data (attenuated backscatter) from two different flights and for times when the aircraft emerged from the cloud top and turned around to fly back over longer stretches above and in the vicinity of the cloud parts which were in situ sampled directly before. The total attenuated backscatter signal is shown, which consists of light scattered from the cloud particles as well as the background contribution due to the air molecules. The coarse color scale is normalized with respect to the values between 2100 and $2400 \mathrm{~m}$, assuming a low and homogeneous aerosol concentration at that altitude. The upper panel shows the backscatter signal from the penetrated boundary layer cloud during Flight 11. During VERDI the encountered clouds mostly consisted of 


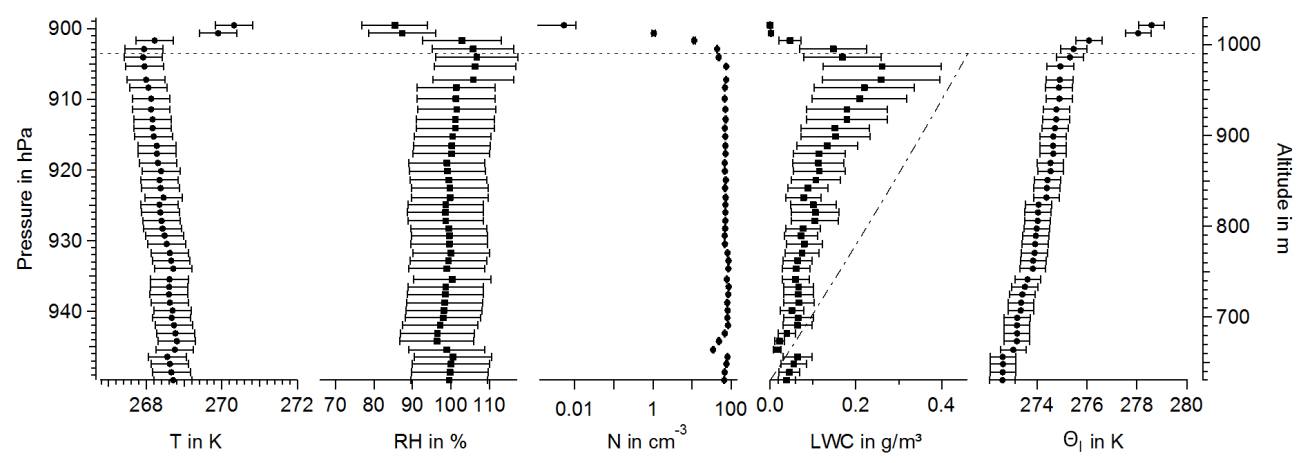

Figure 2. Altitude profiles inside the cloud encountered during Flight 11 (20:05-20:25 UTC) on 15 May 2012. Gradients of temperature $T$ and the relative humidity RH above $990 \mathrm{~m}$ indicate that the cloud is capped by a warmer and drier atmosphere. The droplet number concentration $N$ is constant inside the cloud. LWC and the liquid water potential temperature $\Theta_{1}$ show an increase with altitude. The adiabatic LWC is indicated by the dash-dotted line. The horizontal dashed line marks the beginning of the cloud top transition zone at an altitude of $990 \mathrm{~m}$. The error bars for $T$ and $\mathrm{RH}$ result from the uncertainty of the instruments and the errors for $N$ are very small and based on counting statistics. For LWC and $\Theta_{1}$ the error is calculated by error propagation from the measured parameters.

a)

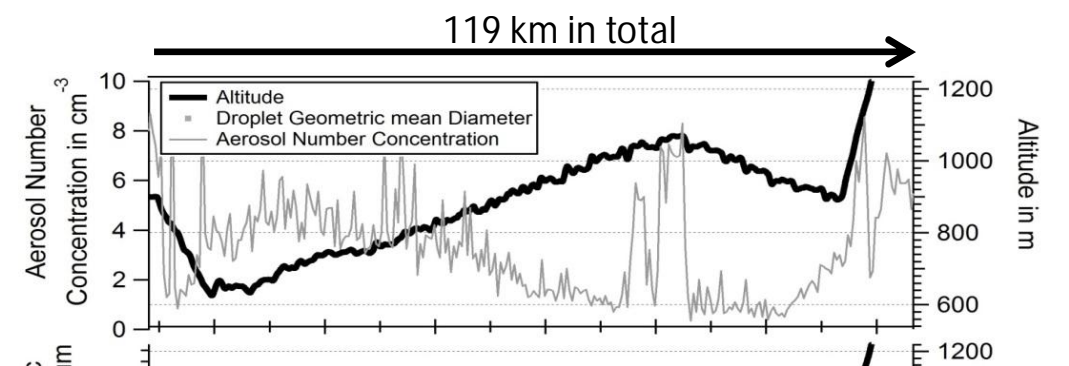

b)

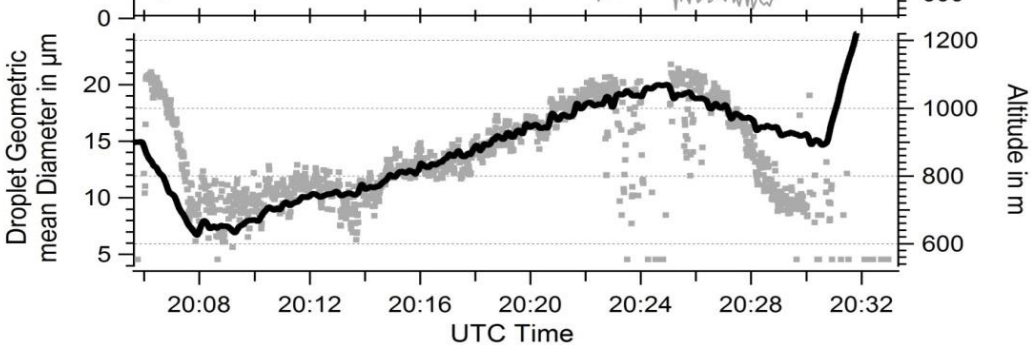

Figure 3. Time series of cloud in situ measurements: aerosol number concentration (a) (grey line) and mean cloud droplet diameter (b) (grey dots) during Flight 11 on 15 May 2012. The flight altitude is indicated in both panels by a solid black line.

several stacked layers with clear air in between, and we did not often find such a "classic" boundary layer cloud deck. The backscatter signal does not show a distinct pattern above the cloud, only a very slight decrease with altitude as time progresses. The values of the attenuated backscatter due to the aerosol are indicative of very low levels of the encountered Arctic aerosol. The penetrated cloud layer was overpassed at 20:41 UTC. In this region, the cloud top height shows no significant changes. As McFarquhar et al. (2011) pointed out substantial changes of cloud top height can occur during a flight. This is the case here too (see Fig. 6a) because at the end of the displayed flight segment the cloud top height is approximately $300 \mathrm{~m}$ lower than at the beginning. In order to highlight the differences compared to other atmospheric conditions, the lower panel (see Fig. 6b) shows the data of Flight 7 on 5 May. During this flight an optically thick aerosol layer $(\mathrm{OD}=0.02 \pm 0.005$ assuming a lidar ratio of $40 \mathrm{sr}$ ) is discernible above the cloud. Since this layer is optically thicker it probably cannot be classified as clean Arctic background aerosol. HYSPLIT reanalysis trajectories over $72 \mathrm{~h}$ (see http://ready.arl.noaa.gov/HYSPLIT.php) indicate that the aerosol originates from Yukon Territories and Alaska in an altitude range between 500 and $1500 \mathrm{~m}$. By contrast reanalysis trajectories for the other days indicate that between 5 and 9 May 2012 air masses containing aerosol were advected mostly from the Canadian and American mainlands.

Every time during Flight 11, when the ascending aircraft penetrated the cloud top, the number concentration of the aerosol particles in a size region between $250 \mathrm{~nm}<D_{p}<1 \mu \mathrm{m}$ increased from $0.7( \pm 0.08) \mathrm{cm}^{-3}$ up to $7.5( \pm 0.02) \mathrm{cm}^{-3}$. Figure $3 \mathrm{a}$ shows this increase 


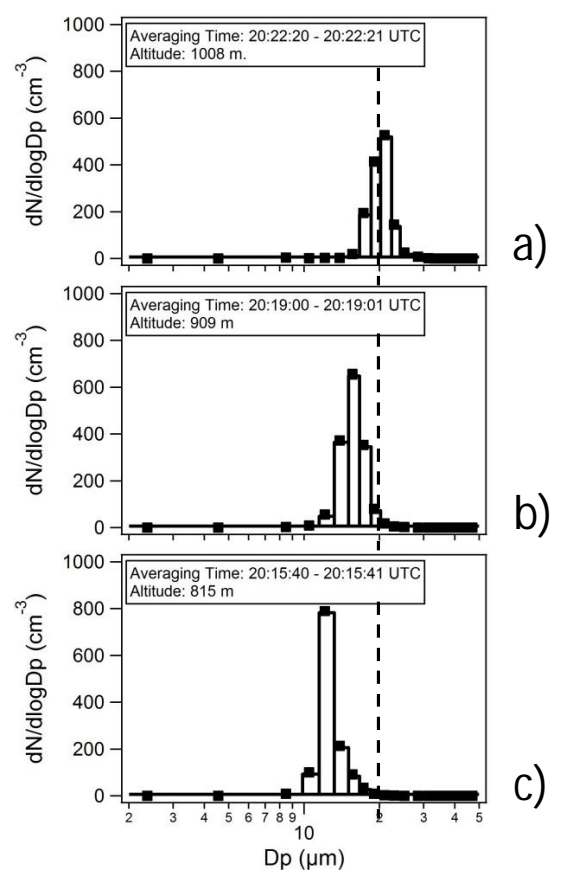

Figure 4. Monomodal cloud droplet size distributions from Flight 11 on 15 May 2012. Note the linear scale of the ordinates with the dashed line marking the $20 \mu \mathrm{m}$ diameter. A continuous increase of the droplet particle diameter with increasing altitude from (c) to (a) is evident.

in the aerosol number concentration at 20:25:00 and 20:31:30 UTC. Aerosol particle SDs from the OPC measurements are shown in Fig. 7. In order to provide a comparison with a typical clean atmosphere encountered during VERDI, a Sky-OPC SD from Flight 10 on 14 May is added and from the error bars (based on counting statistics) the range of variability can be seen. The aerosol number concentration above the cloud, particularly for smaller sizes between $250 \mathrm{~nm}<D_{p}<500 \mathrm{~nm}$, is by a factor of about seven higher than inside the cloud. Unfortunately, for detecting particles smaller than $250 \mathrm{~nm}$ no instrument was available during the VERDI campaign. For this reason, the averaged dry Arctic background aerosol SD, which was measured and reported as regional average by Lathem et al. (2013) with a Scanning Mobility Particle Sizer (SMPS), is adapted and also included in Fig. 7.

(Note: In addition to the SMPS system Lathem et al. (2013) used a Cloud Condensation Nuclei Counter (CCNC) to determine the fraction of aerosol that can be activated to cloud droplets. They found an activation ratio of 0.52 (at $0.55 \%$ internal supersaturation inside the instrument) which shows that approximately half of the measured cloud nuclei $(\mathrm{CN})$ were activated.)

Despite the uncertainties inherent in a comparison of measurements which were four years apart, this juxtaposition shows that the aerosol concentrations from the single mea- surements during VERDI match quite well with - or at least do not strongly deviate from - the previously mapped regional average. In particular the background aerosol particles measured above the cloud during VERDI do not exhibit largely different number densities than those reported by Lathem et al. (2013). Therefore, the detected aerosol above the cloud on 15 May 2012, might well be considered as dry Arctic background aerosol which seems to be continuously present in this region. The aerosol number concentrations above the cloud from 5 May, however, are significantly higher than the background typically found during VERDI.

\subsection{Spatial distribution of the droplets from the bimodal size distributions}

To exclude the possibility that the bimodal SDs are result of a sampling artifact caused by time-averaging over spatially separated particle populations with different size modes, the $\mathrm{PbP}$ data from the CDP were examined. In this way the sizes and the exact detection times for consecutive single detected particles become available. Figure 8a shows a plot based on $\mathrm{PbP}$ analysis for data collected during a $3.5 \mathrm{~s}$ period (i.e., a flight segment of roughly $254 \mathrm{~m}$ length) from Flight 11 , which is the particular period where the bimodal SD shown in Fig. 5c was observed. Figure 8a displays a time series of the individual particle detections with the two size modes separated by the dashed line with Mode 1 covering particle diameters around $20 \mu \mathrm{m}$ and Mode 2 those around $10 \mu \mathrm{m}$. Overall, 1023 particles were recorded in this period. The time gaps, where no consecutive particles are displayed, result from the limited buffer capacity and transmission speed (i.e., a maximum of 256 particles in one second) of the $\mathrm{PbP}$ recording of the CDP. The contiguous PbP-record segments in Fig. $8 \mathrm{a}$ are roughly $0.3 \mathrm{~s}$ long and correspond to about $20 \mathrm{~m}$ of flight distance within the cloud. To illustrate the mixing state of both modes, the detected particles are labeled with two colors. The red color dots represent particles where the previously detected particle was from the same size mode. The black dots mark particles where the previously detected particle originated from the other mode. If the aircraft had moved through one patch of air containing only Mode 1 particles (like in the SDs of Fig. 4) and afterwards through a different air parcel with mostly droplets from Mode 2 - for example because the two parcels were from different entrainment filaments - then a bimodal SD might result from data averaging over a sufficiently long flight path stretch. In this case the PbP "arrival time analysis", however, would have revealed such effects. To investigate the mixing of the two modes on such scales a statistical approach is used by comparing the probabilities of black and red dots to those of an ideal mixing state where particles from any of the two modes are detected at random. The probability of detecting two successive particles from two different size modes in a fully ran- 


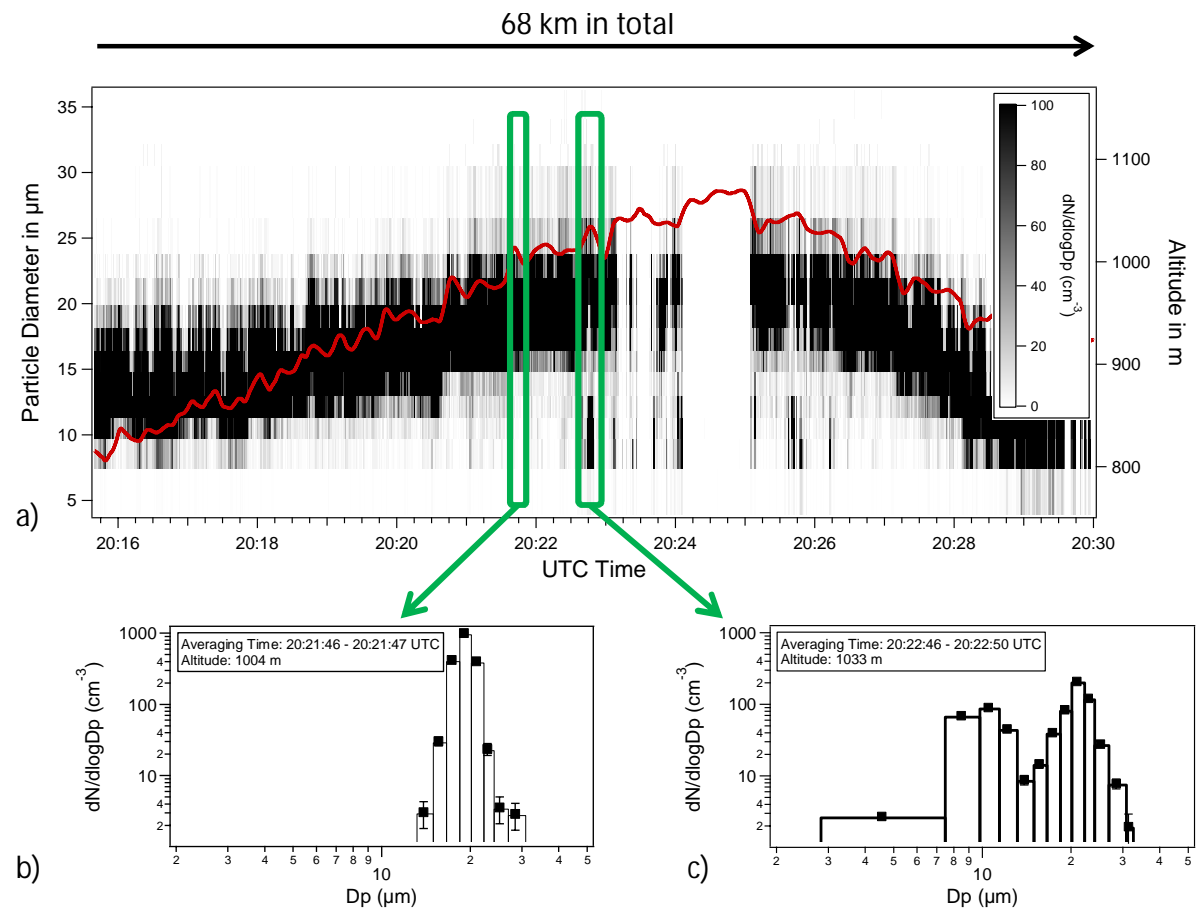

Figure 5. Upper panel: time series of measured cloud particle data from Flight 11 on 15 May 2012. The contour plot displays particle diameters over time, the greyscale encodes the number concentration and the red line represents the flight altitude. Lower panel: two different droplet size distributions: (b) as detected inside the cloud and (c) in the cloud top transition zone. Bimodal size distributions only occur in the cloud top transition zone.
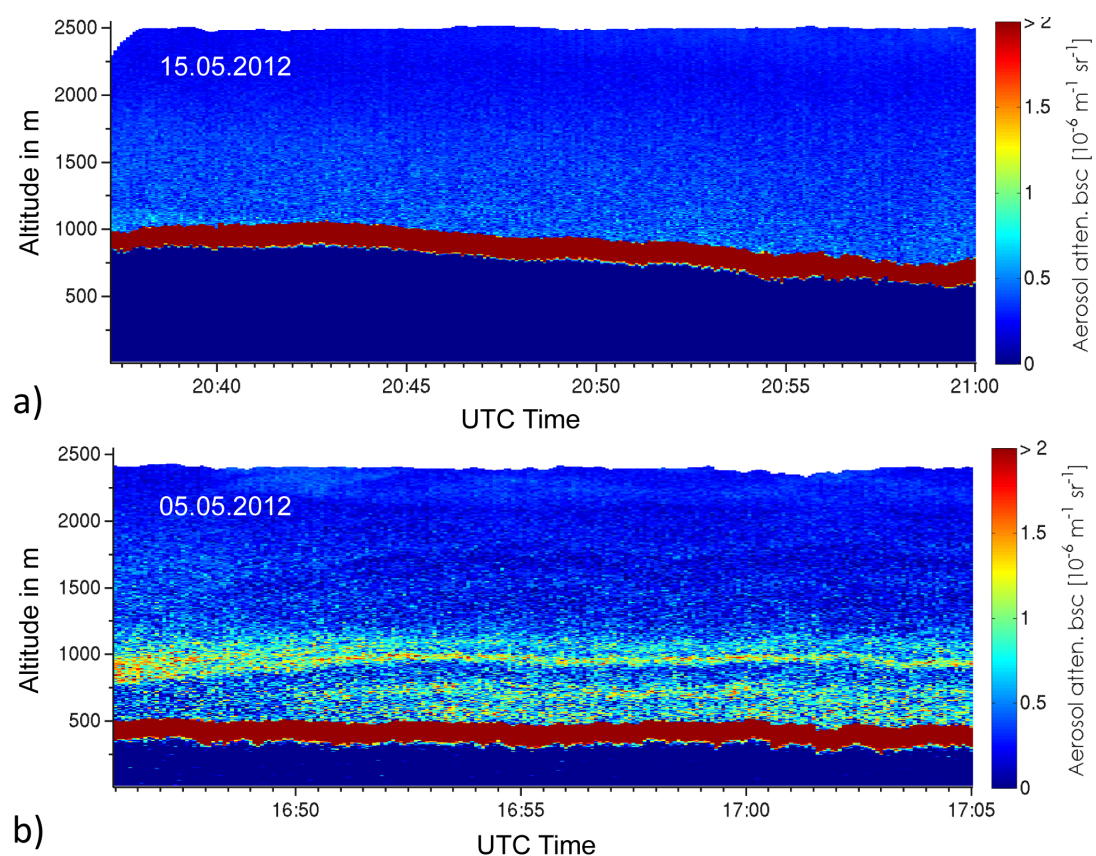

Figure 6. (a) AMALi Lidar backscatter signal from the studied boundary cloud layer in comparison with measurements including a thick aerosol layer above a cloud layer (b). 


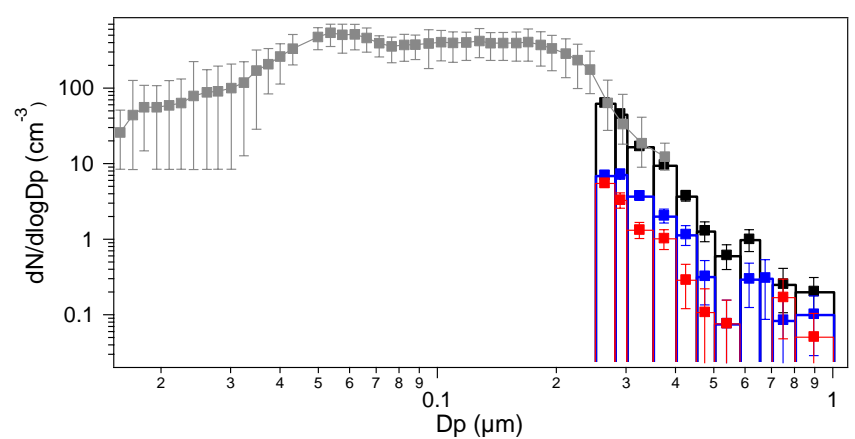

- May 15, 2012 - OPC SD above the cloud (Time average: 20:24:10 - 20:25:04 UTC) - May 15, 2012 - OPC SD inside the cloud (Time average: 20:21:40 - 20:22:34 UTC) May 14,2012 - cleanest atmosphere (Time average: 20:36:42 - 20:37:36 UTC) Dry arctic background particles, Adapted from Lathem et al. (2012)

Figure 7. Cloud droplet size distributions from Flight 11 on 15 May 2012 in comparison with measurements during a cloud free, clear air situation from Flight 10 on May 14, 2012. The error bars denote the uncertainties due to the counting statistics while the width of the columns indicates the size bin limits. The data shown for sizes below $0.4 \mu \mathrm{m}$ (grey line and symbols) are SMPS measurements from Lathem et al. (2013) reflecting the regional background aerosol levels from spring time in 2008.

dom process is:

$\mathrm{P}_{12+21}=p_{1} p_{2}+p_{2} p_{1}=2\left(p_{1}\left(1-p_{1}\right)\right)=2 p_{1}-2 p_{1}^{2}$,

with $p_{1}$ and $p_{2}$ designating the occurrence rates (i.e., the probabilities) of particles from Mode 1 and Mode 2 and with $p_{1}+p_{2}=1$. Figure 9 displays $P_{12+21}$ from Eq. (1) as black line.

Consider as an example that 100 particles were successively detected with 60 (i.e., a value of 0.6 on the abscissa) originating from Mode 2 and 40 from Mode 1. In this case the probability of having two random consecutive particles and finding them in different modes is in theory $48 \%$ as taken from the ordinate in Fig. 9. For the measured example (i.e., the bimodal SD detected between 20:22:46 and 20:22:50 UTC on Flight 11), however, it was $44.7 \%$ and in this case, the bimodal SD shown in Fig. 8a is close to a uniform distribution. The mean interarrival time between the individual particles is $1.45 \mathrm{~ms}$. Therefore, with an aircraft speed of $70 \mathrm{~m} \mathrm{~s}^{-1}$, the mean distance between two detected particles is roughly $10 \mathrm{~cm}$. It can be concluded that within this detection rate, limited by the nearly one-dimensional sample volume of the instrument, both size modes are well mixed on the decimeter scale. Figure $8 b$ provides similar data based on $\mathrm{PbP}$ analysis from the same flight at an earlier time. Apparently here the black and red dots are mostly clustered either in Mode 1 or in Mode 2. Thus the two modes were sampled as disjoint droplet populations. Averaging over the corresponding flight stretch would deliver a bimodal distribution although both modes are in separate cloud droplet populations. This demonstrates how potential sampling artifacts resulting from averaging can be identified by $\mathrm{PbP}$ analyses.
Further bimodal SDs from Flight 9 and Flight 13 were examined this way and also integrated in Fig. 9. In summary, four bimodal SDs (marked by circles) seem to result from well mixed air parcels. For the other three bimodal SDs, the agreement with the uniform distribution is less pronounced which suggests clustering of particles in each single mode (on sub-meter scale). In these mostly clustered cases, the cloud droplets essentially were sampled from two disjoint particle ensembles.

\section{Theoretical considerations and modeling}

We first consider the possibility that the entrainment of dry aerosols from the free atmosphere might lead to cloud droplet nucleation, and the formation of the second mode in the SD (around $10 \mu \mathrm{m}$ ). This process was invoked by Lawson et al. (2001) to explain the bimodal SDs in their observations. Further aerosol effects on ice nucleation, entrained in Arctic clouds, were observed and analyzed by Jackson et al. (2012) and Earle et al. (2011).

Isobaric mixing can lead to the necessary supersaturation for condensation if the saturation-vapor-pressure curve is sufficiently nonlinear over the temperature range relevant for the mixing. Figure 10 shows the saturation-vapor-pressure curve in comparison with the studied case from the flight of 15 May 2012. The saturation-vapor-pressure curve is almost linear in the range covered by the measurements, indicating that the condensation of new droplets in the mixing is not possible. This argument can be substantiated by discussing the total droplet number concentration. For the second mode (around $10 \mu \mathrm{m}$ ) in Fig. 5c, in a size range between 2.8 and $13 \mu \mathrm{m}$, the total droplet number concentration is $15.3 \mathrm{~cm}^{-3}$. In comparison, this is twice as much as the aerosol number concentration (see Fig. 3a), which is around $7.5 \mathrm{~cm}^{-3}$. This means that more droplets develop in the second mode than there are available aerosol particles. Nevertheless, we cannot exclude the possibility that single aerosol particles are activated, but evaporation processes seem to be the major effect. A "closure experiment" according to McFarquhar et al. (2011) where the particle numbers from inside the cloud match those of the aerosol particles from above the cloud could not be performed here because our instruments did not cover a broad enough size range.

In this section we describe direct numerical simulation (DNS) model calculations and results in order to try to explain the observed bimodal SDs in the cloud top entrainment zone. The main assumption is that the bimodal SDs result from the turbulent mixing dynamics at the stratocumulus top, which is supported by the fact that all bimodal SDs were observed close to the cloud top, in contrast to the monomodal SDs encountered inside the cloud. Direct numerical simulations were adopted (rather than, e.g., large eddy simulations) to demonstrate how the turbulent mixing dynamics at the stratocumulus top can generate bimodal SDs 
a)
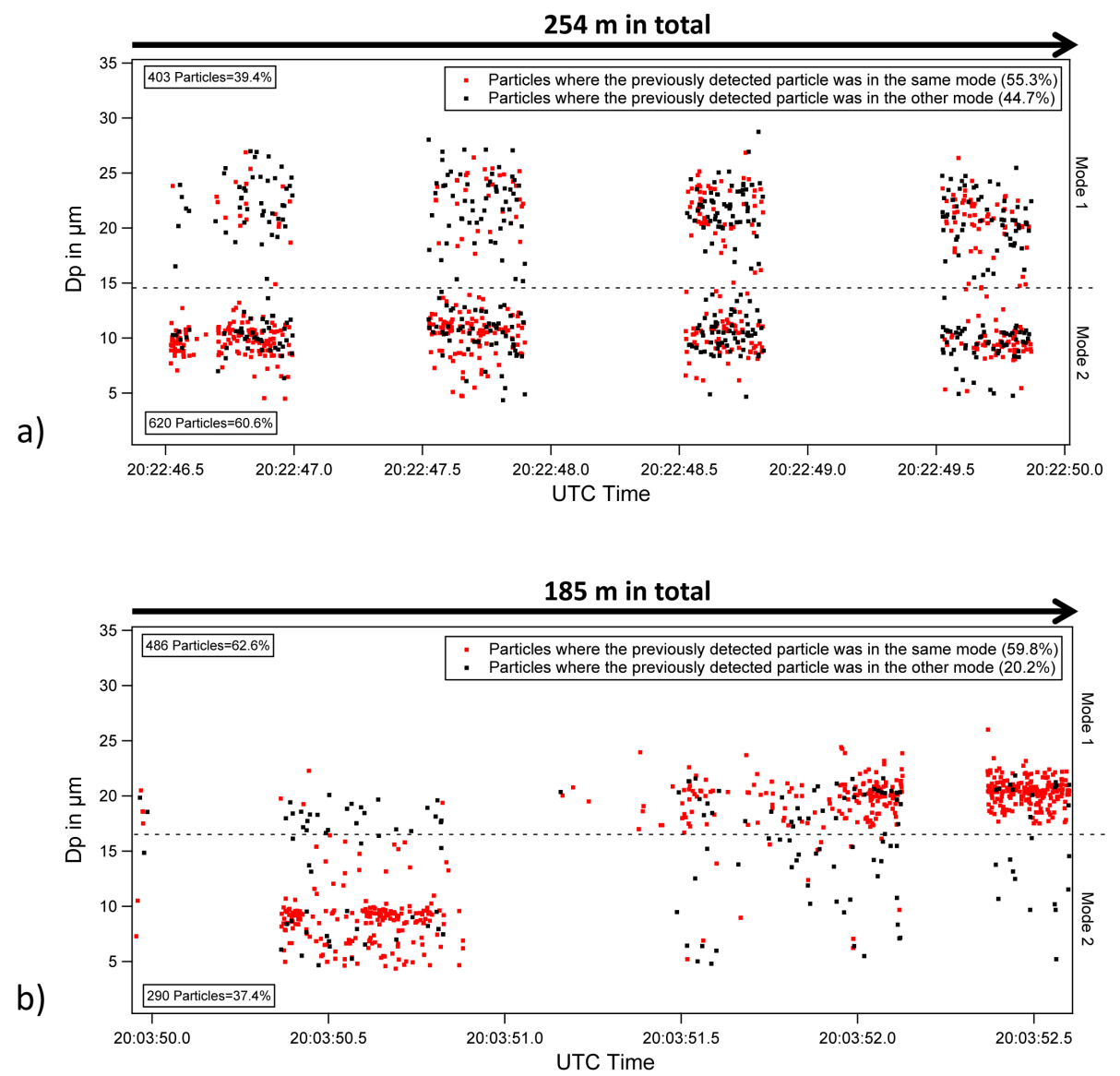

Figure 8. Time slice of Flight 11 on 15 May 2012 with particle-by-particle ( $\mathrm{PbP})$ data: the detected particles are separated in Mode 1 and Mode 2. The red points mark particles where the previous detected particle was in the same mode. Black points mark particles where the previous detected particle was in the other size mode. (a) represents a good mixing behavior and more particles $(60.6 \%)$ were detected in Mode 2. (b) indicates a clustered case where most of the particles are in Mode 1.

similar to the observed ones. The two main mechanisms for turbulent mixing in stratocumulus are infrared radiative cooling and evaporative cooling. By means of Doppler X-band radar measurements McFarquhar et al. (2011) showed that such turbulent effects occur in the Arctic boundary layer cloud systems. Close to the cloud top infrared radiation cools parcels that "fall back down into" the cloud, initiating turbulence and mixing. Turbulent mixing entrains dry air from the free atmosphere above the cloud, causing the evaporation of cloud droplets. The evaporative cooling involved in this process can in turn considerably enhance the turbulent mixing at the cloud top, depending on the thermodynamic properties of the cloud and adjacent free atmosphere. In some cases a horizontal wind shear can be strong enough to contribute or even dominate the mixing process.

As next step, three-dimensional DNS of a mixing layer were used in order to test the hypothesis that turbulent mixing and evaporation can explain the bimodal SDs.

Mellado (2010) and de Lozar and Mellado (2014) showed that simulations of such a simplified configuration are a valid approach for the investigations of cloud-top mixing. DNS provide a faithful representation of the mixing, even at the smallest resolved scales, which is necessary to investigate how the small-scale turbulent mixing modifies the SD. In our calculations we simulate scales from a Kolmogorov length $\eta=15 \mathrm{~cm}$ to an integral length scale of $200 \mathrm{~m}$, thus capturing the relevant scales for mixing. The main limitation of DNS is that current studies are constrained to small and simplified setups, due to their great computational cost. For this reason our simulations are driven only by infrared radiative cooling and evaporative cooling, and we neglect other cloud processes, like microphysics, surface fluxes, shear, rain or short-wave radiation. Although those processes might have an influence on the cloud dynamics, estimates show that their contribution to the turbulence and droplet growth is relatively small when compared to radiative and evaporative cooling (for example see Stevens et al., 2005 and Bretherton et al., 2007). For this reason those processes are probably not strong enough to change qualitatively the small-scale mixing behavior. 


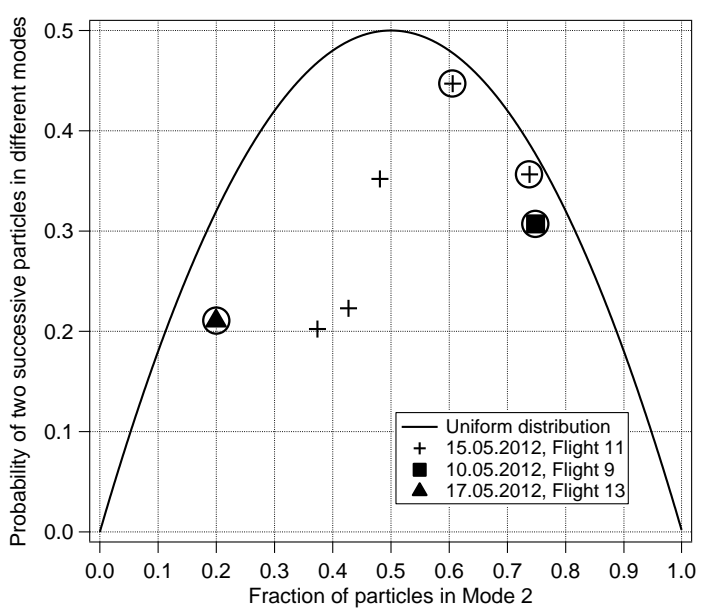

Figure 9. Statistical "proximity" analysis for the measured bimodal droplet size distributions. The black line shows a theoretical, uniform distribution between both modes. The results from Fig. 8a (i.e., abscissa $=0.606=60.6 \%$ and ordinate $=0.447=44.7 \%$ ) indicate that the measured bimodal size distribution is close to uniform distribution. Four of the seven bimodal size distributions (marked by circles) show a good agreement with the theoretical, uniform distribution.

The set of governing equations is based on the onemoment bulk scheme described in de Lozar and Mellado (2013). The equations are further simplified by linearizing the buoyancy and the saturation-vapor-pressure functions around a reference state. The resulting formulation is equivalent to the one presented by Bretherton (1987), and is subject of a forthcoming manuscript. In this approximation the saturation-vapor-pressure function is linear, and therefore the isobaric condensation mixing is neglected. The long-wave radiation model is a one-dimensional model, that assumes that radiation only propagates in the vertical direction (Larson et al., 2007).

The thermodynamic parameters used in the simulation are based on the measurements from the flight of 15 May 2012: $\mathrm{LWC}=0.25 \mathrm{~g} \mathrm{~kg}^{-1}$, the sum of the vapor and liquid water content $q_{t}=3.15 \mathrm{~g} \mathrm{~kg}^{-1}, T=268.15 \mathrm{~K}$ and $\Theta_{1}=275.2 \mathrm{~K}$ in the cloud layer; and $q_{t}=2.4 \mathrm{~g} \mathrm{~kg}^{-1}, T=272.65 \mathrm{~K}, \mathrm{RH}=$ $59 \%$ and $\Theta_{1}=280.5 \mathrm{~K}$ in the dry air layer above the cloud. The atmospheric pressure is $905 \mathrm{hPa}$. The cloud-top radiative cooling, $F_{0}=60 \mathrm{~W} \mathrm{~m}^{-2}$, matches the data from the instruments on board the POLAR 5, and an extinction length was chosen to $\lambda=15 \mathrm{~m}$ (see Larson (2007) and de Lozar and Mellado (2014) for an explanation of the radiation parameters). The simulation runs for $12 \mathrm{~min}$ and covers for the turbulence length scales from $15 \mathrm{~cm}$ to $200 \mathrm{~m}$. The grid employed in the numerical simulations contains $1024^{3}$ points, the width of the simulation domain is $270 \mathrm{~m}$ and the resulting grid spacing in the region of interest is $26 \mathrm{~cm}$.

Figure 11 shows a vertical cross section from our simulations, in which the liquid water density ranges from

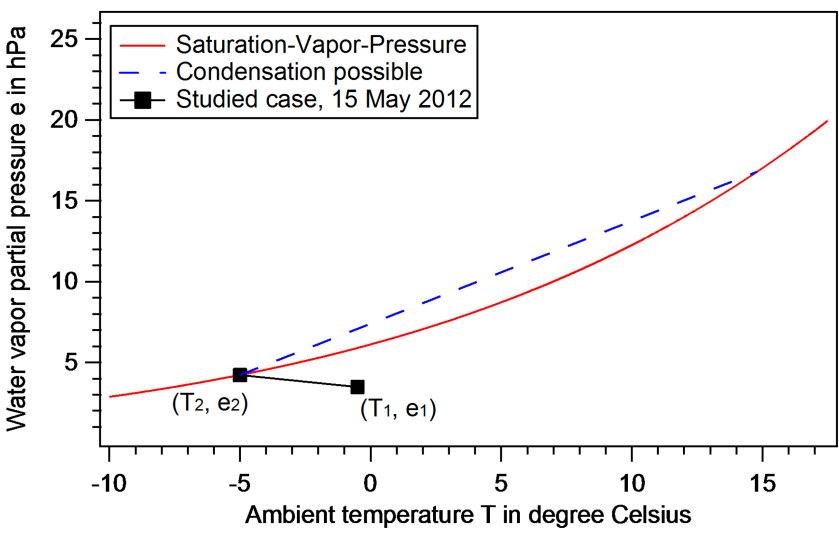

Figure 10. Isobaric mixing diagram for parcels of cloudy and a dry air: the red line denotes the water vapor partial pressure for saturation, and the blue dashed line exemplifies a mixing line along which the cloudy air parcel $\left(T_{2}, e_{2}\right)$ could have been mixed with another parcel such that supersaturation results. However, for the studied case from Flight 11 on 15 May 2012 (as represented by the short, straight, black line) no conditions for supersaturation and for aerosol particle activation arise. (The thermodynamic parameters of $T_{1}=-0.5^{\circ} \mathrm{C}, \mathrm{RH}_{1}=59 \%, e_{1}=3.5 \mathrm{hPa}$ for dry air and $T_{2}=-5^{\circ} \mathrm{C}, \mathrm{RH}_{2}=100 \%, e_{2}=4.2 \mathrm{hPa}$ inside the cloud are based on the measurements.)

$0.0 \mathrm{~g} \mathrm{~kg}^{-1}$ (blue) to $0.325 \mathrm{~g} \mathrm{~kg}^{-1}$ (white). Turbulence and mixing are evident in the transition zone between the cloudy air and the free dry atmosphere, as it is typical for stratocumulus clouds. In the transition zone the entrained air concentrates on some regions that are indicated by red squares in Fig. 11. We specify these regions as "holes", in analogy to the liquid free regions observed by Gerber et al. (2005) in some tropical clouds. In comparison to the previously observed holes (Gerber et al., 2005), the holes in our simulations contain more liquid water and stay closer to the cloud top. These differences are explained by the relatively high humidity of the free atmosphere measured in the flight of 15 May $2012(\mathrm{RH}=59 \%)$ above the cloud. The potential for evaporation is lower and therefore it is not surprising that some liquid water droplets still are present in the holes after the mixing process. Given the combination of low cloud water concentration and still enough water vapor in the free atmosphere, the evaporative cooling is expected to be low. As a consequence the air in the holes is mostly positively buoyant, and the holes have a tendency to remain close to the cloud top.

Our hypothesis is that the bimodal SDs shown in Fig. 5c are a result of the mixing within the holes. For testing we simulated the SD that an aircraft would measure in our model, when flying close to the cloud top (black line in Fig. 11). The mean diameter of the droplets in each grid box was calculated using the liquid water from the simulations and a droplet number concentration $N=70 \mathrm{~cm}^{-3}$ as measured, e.g., in Fig.2. For the last $70 \mathrm{~m}$ (equivalent to $1 \mathrm{~s}$ of flight 


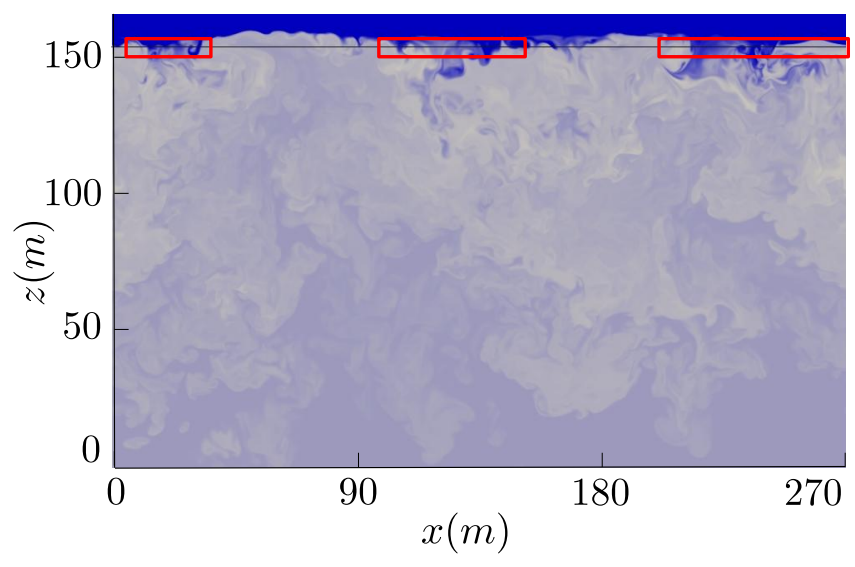

Figure 11. Results from direct numerical simulation of the turbulence in the cloud top entrainment zone: vertical cross section of the calculated cloud liquid water with the color scale extending from $0.0 \mathrm{~g} \mathrm{~kg}^{-1}$ (blue) to $0.325 \mathrm{~g} \mathrm{~kg}^{-1}$ (white). The black line indicates the simulated aircraft trajectory through the scenario and the red rectangles mark the "cloud holes", i.e., air parcels mostly of cloud free air.

time for the POLAR 5) of the simulated plane trajectory (including the big hole highlighted by the bounding box) the SD shows a bimodal shape (see Fig. 13) which at least qualitatively agrees with the measured ones in Fig. 5c. Even though the minima between the two modes in the SDs are $4 \mu \mathrm{m}$ apart and the number concentrations of the large droplet mode are quite different the SD are similar enough to suggest that the evaporation of droplets in the holes causes the bimodality.

The second mode in the SDs in the simulations can be explained if we assume that the large-scale dynamics of each hole are dominated by a single large eddy, while the rapid mixing inside the holes is due to much smaller turbulent eddies. The time scale of the large eddy determines the mixing and composition inside a hole, defining a typical droplet diameter: large eddies are able to capture large quantities of dry air resulting in a small typical droplet diameter, while smaller eddies are characterized by larger droplet diameters. This can be seen in Figs. 11 and 12 where large and small holes occur. For example the rightmost red box in Fig. 11 contains such a large hole (i.e., a large parcel of drier air) yielding in the simulation many small "Mode 2" droplets. Most likely the second mode with the smaller droplets in the SD represents the typical droplet diameter of the hole in the bounding box, whereas the first, larger droplet mode corresponds to cloud droplets that have not yet been mixed. A second simulation for a different flight sequence from Flight 13 also yielded to a good agreement between measured and calculated SD. Further, more extensive simulations with detailed sensitivity studies concerning the various governing parameters are necessary here together with similar comparisons to field data, which should also cover different thermodynamic situations (e.g., moisture, temperature above the

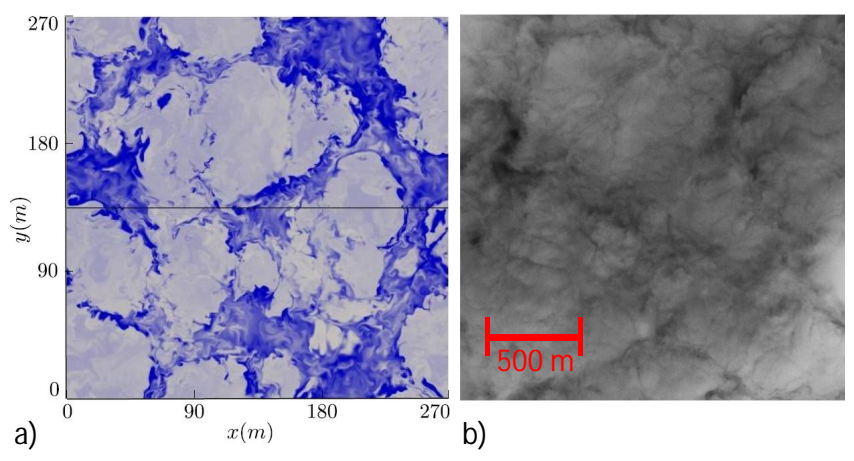

Figure 12. (a) DNS simulation of the horizontal cross section for cloud liquid water content. The simulated aircraft trajectory is given by the black line and the scaling of the color code is the same as in Fig. 11. (b) Photograph, taken by a camera mounted at the fuselage of the POLAR 5 aircraft showing the top of the boundary layer cloud deck which was observed during Flight 11. The scales of (a) and (b) are different but the self-similarity of the structures is demonstrated qualitatively for the cloud encountered in the real atmosphere and the simulated cloud liquid water patterns.

clouds). Since such DNS are very expensive in terms of computational time, juxtaposition of the results with those from other approaches for numerical simulations, like Large Eddy Simulation (LES), are also of advantage. To analyze this phenomenon in a higher resolution a holographic instrument capable of detecting particles in a three-dimensional sample volume of a few $\mathrm{cm}^{3}$ in a single snapshot (Spuler and $\mathrm{Fu}-$ gal, 2011; Schlenczek et al. 2014) allows investigation of still smaller mixing scales for both size modes. Also new imaging remote sensing techniques (e.g., as presented by Bierwirth et al., 2013) could help to identify the horizontal variability of the cloud top regions on different scales and thus to quantify the interplay between eddy driven mixing and cloud microphysical processes.

\section{Conclusions}

The VERDI campaign was performed to study microphysical and radiative properties of Arctic boundary layer clouds in the Beaufort Sea area. Previous microphysical measurements have shown the occurrence of monomodal and bimodal size distributions caused by adiabatic ascent and activation of new CCN, which were entrained. In the VERDI campaign similar size distributions were observed in boundary layer stratus and stratocumulus clouds during three flights including monomodal size distributions with the modal peak size varying between 12 and $22 \mu \mathrm{m}$ dependent on altitude within the cloud. Measurements of the LWC indicate deviations from adiabatic conditions and, therefore, entrainment processes at the top of the penetrated cloud deck play a role. Lidar and aerosol instruments above the cloud layers showed a well mixed aerosol particle population which can be clas- 


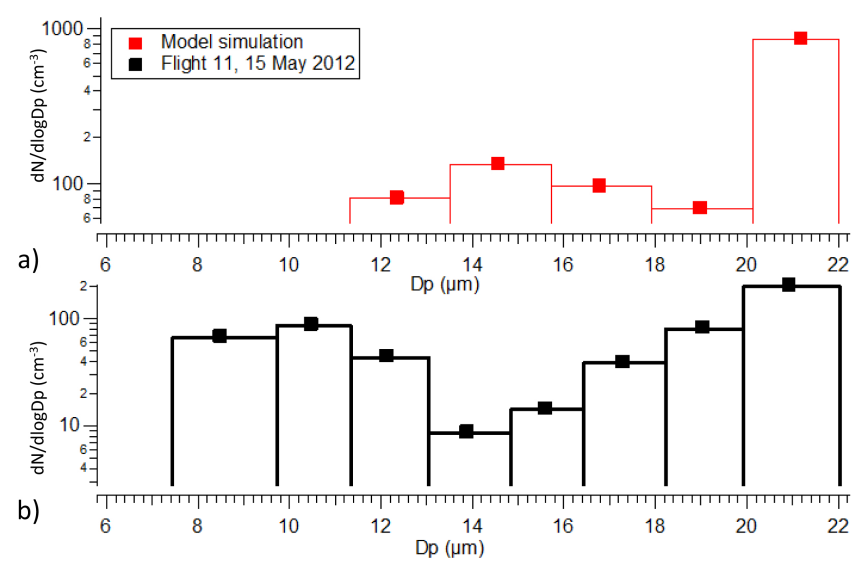

Figure 13. (a) A bimodal size distribution of the cloud droplets as obtained from the direct numerical simulation for the last $70 \mathrm{~m}$ of the simulated aircraft trajectory. (b) For comparisons the measured bimodal size distribution from Flight 11 as also shown in Fig. 5c.

sified as dry Arctic background aerosol. In the cloud transition zone at altitudes between 990 and $1060 \mathrm{~m}$ a change from monomodal towards bimodal cloud droplet size distributions was observed. A method adopting particle interarrival times was applied to study the mixing progress between both droplet modes ultimately demonstrating that for four of seven cases with bimodal droplet size distributions a nearly uniform mixing process prevailed. This means that an artifact due to (flight) time averaging over two spatially separated particle population can be excluded down to scales of a decimeter. The other cases indicate a sampling from two disjoint particle ensembles.

The development of the second mode in the transition zone could in principle be explained (a) by activation/condensation of newly entrained $\mathrm{CCN}$ or (b) by evaporation processes. Condensation from isobaric mixing is only possible for configurations with large deviations in temperature and water vapor concentration. In the measurements the temperature variations between cloud and free atmosphere are so small that the saturation-vapor-pressure curve is almost linear in this range, making isobaric condensation of new droplets impossible. For this reason evaporation processes were examined in more detail by using a model simulation study adopting Direct Numerical Simulations of turbulent eddy ensembles covering length scales from $15 \mathrm{~cm}$ (i.e., the Kolmogorov range) to eddies as large as $200 \mathrm{~m}$. This model considered evaporative and radiative cooling and produces regions with concentrated entrained air. The resulting simulated bimodal cloud droplet size distributions in the cloud top entrainment zone are in qualitative agreement with the size distributions obtained from the in situ measurements. Turbulent entrainment of clear-air-eddies seem to be the cause for the development of the second droplet size mode (at $10 \mu \mathrm{m}$ diameter) whereas the first size mode (near
$20 \mu \mathrm{m})$ represents droplets that have not yet been mixed with the drier air from above.

In conclusion, inside the transition zone of the observed boundary layer clouds we detected bimodal size distributions where the smaller size mode seems to be a result from eddy driven in-mixing of drier air with subsequent evaporation. More extensive experimental studies in real atmospheric clouds and simulations with different numerical methods focused on the cloud top entrainment zone of stratus and stratocumulus - are necessary. These should cover different thermodynamic and cloud microphysical parameter ranges to ultimately extend towards other cloud types as well.

Acknowledgements. This work was supported by internal sources of the Max Planck Society (Mainz and Hamburg) with additional funds for the instrument integration and the research flights by the Alfred Wegener Institute for Polar and Marine Research (Bremerhaven, Germany). We thank the staff of the Aurora Research Institute (here the Western Arctic Research Center, WARC, in Inuvik, NWT, Canada) for their commendable support and hospitality during the VERDI campaign. The support by the electrical engineers Wilhelm Schneider and Christian von Glahn (University of Mainz) is very much appreciated. We particularly thank the scientists, the pilots and the crew of the POLAR 5, as well as all other VERDI participants and contributors. Computational time was provided by the Jülich Supercomputing Centre. We would also like to thank Darrel Baumgardner and two anonymous reviewers for their diligence and thoughtful suggestions.

Edited by: P. Eriksson

\section{References}

Avramov, A., Ackerman, A. S., Fridlind, A. M., van Diedenhoven, B., Botta, G., Aydin, K., Verlinde, J., Korolev, A. V., Strapp, J. W., McFarquhar, G. M., Jackson, R., Brooks, S. D., Glen, A., and Wolde, M.: Toward ice formation closure in Arctic mixed-phase boundary layer clouds during ISDAC, J. Geophys. Res.-Atmos., 116, D00T08, doi:10.1029/2011jd015910, 2011.

Betts, A. K.: Non-precipitating cumulus convection and its parameterization, Q. J. Roy. Meteor. Soc., 99, 178-196, 1973.

Bierwirth, E., Ehrlich, A., Wendisch, M., Gayet, J.-F., Gourbeyre, C., Dupuy, R., Herber, A., Neuber, R., and Lampert, A.: Optical thickness and effective radius of Arctic boundary-layer clouds retrieved from airborne nadir and imaging spectrometry, Atmos. Meas. Tech., 6, 1189-1200, doi:10.5194/amt-6-1189-2013, 2013.

Bretherton, C. S.: A theory for nonprecipitating moist convection between 2 parallel plates 1: Thermodynamics and linear solutions, J. Atmos. Sci., 44, 1809-1827, 1987.

Bretherton, C. S., Blossey, P. N., and Uchida, J.: Cloud droplet sedimentation, entrainment efficiency, and subtropical stratocumulus albedo. Geophys. Res. Lett., 34, L03813, doi:10.1029/2006GL027648, 2007.

Curry, J. A., Rossow, W. B., Randall, D., and Schramm, J. M.: Overview of Arctic cloud and radiation characteristics, J. Climate, 9, 1731-1764, 1996. 
Curry, J. A., Hobbs, P. V., King, M. D., Randall, D. A., Minnis, P., Isaac, G. A., Pinto, J. O., Uttal, T., Bucholtz, A., Cripe, D. G., Gerber, H., Fairall, C. W., Garrett, T. J., Hudson, J., Intrieri, J. M., Jakob, C., Jensen, T., Lawson, P., Marcotte, D., Nguyen, L., Pilewskie, P., Rangno, A., Rogers, D. C., Strawbridge, K. B., Valero, F. P. J., Williams, A. G., and Wylie, D.: FIRE Arctic Clouds Experiment, Bull. Amer. Meteor. Soc., 81, 5-29, 1999.

de Lozar, A. and Mellado, J. P.: Direct Numerical Simulations of a Smoke Cloud-Top Mixing Layer as a Model for Stratocumuli, J. Atmos. Sci., 70, 2356-2375, doi:10.1175/jas-d-12-0333.1, 2013.

de Lozar, A. and Mellado, J. P.: Cloud droplets in a bulk formulation and its application to buoyancy reversal instability, Q. J. Roy. Meteor. Soc., 140, 1493-1504, doi:10.1002/qj.2234, 2014.

Earle, M. E., Liu, P. S. K., Strapp, J. W., Zelenyuk, A., Imre, D., McFarquhar, G. M., Shantz, N. C. and Leaitch, W.R.: Factors influencing the microphysics and radiative properties of liquid-dominated Arctic clouds: Insight from observations of aerosol and clouds during ISDAC, J. Geophys. Res., 116, 16, doi:10.1029/2011JD015887, 2011.

Ehrlich, A., Wendisch, M., Bierwirth, E., Herber, A., and Schwarzenböck, A.: Ice crystal shape effects on solar radiative properties of Arctic mixed-phase clouds - Dependence on microphysical properties, Atmos. Res., 88, 266-276, 2008a.

Ehrlich, A., Bierwirth, E., Wendisch, M., Gayet, J.-F., Mioche, G., Lampert, A., and Heintzenberg, J.: Cloud phase identification of Arctic boundary-layer clouds from airborne spectral reflection measurements: test of three approaches, Atmos. Chem. Phys., 8, 7493-7505, doi:10.5194/acp-8-7493-2008, 2008b.

Ehrlich, A., Wendisch, M., Bierwirth, E., Gayet, J.-F., Mioche, G., Lampert, A., and Mayer, B.: Evidence of ice crystals at cloud top of Arctic boundary-layer mixed-phase clouds derived from airborne remote sensing, Atmos. Chem. Phys., 9, 9401-9416, doi:10.5194/acp-9-9401-2009, 2009.

Fan, J., Ovtchinnikov, M., Comstock, J. M., McFarlane, S. A., and Khain, A.: Ice formation in Arctic mixed-phase clouds: Insights from a 3-D cloud-resolving model with size-resolved aerosol and cloud microphysics, J. Geophys. Res. , 114, D04205, doi:10.1029/2008JD010782, 2009.

Field, P. R., Wood, R. and Brown, P. R. A.: Ice Particle Interarrival Times Measured with a Fast FSSP, J. Atmos. Oceanic Technol., 20, 249-261, 2003.

Field, P. R., Heymsfield, A. J., and Bansemer, A.: Shattering and Particle Interarrival Times Measured by Optical Array Probes in Ice Clouds, Amer. Meteor. Soc., 23, 1357-1371, 2006.

Gerber, H., Frick, G., Malinowski, S. P., Brenguier, J. L., and Burnet, F.: Holes and entrainment in stratocumulus, J. Atmos. Sci., 62, 443-459, 2005.

Hansen, J., Ruedy, R., Sato, M., and Lo, K.: Global surface temperature change, Rev. Geophys., 48, RG4004, doi:10.1029/2010RG000345, 2010.

Huebert, B. J., Howell, S. G., Covert, D., Bertram, T., Clarke, A., Anderson, J. R., Lafleur, B. G., Seebaugh, W. R., Wilson, J. C., Gesler, D., Blomquist, B., and Fox, J.: PELTI: Measuring the Passing Efficiency of an Airborne Low Turbulence Aerosol Inlet, Aerosol Sci. Tech., 38, 803-826, 2004.

Jackson, R. C., McFarquhar G. M., Korolev, A. V., Earle, M. E., Liu, P. S. K., Lawson, R. P., Brooks, S., Wolde, M., Laskin, A., and Freer, M.: The dependence of ice microphysics on aerosol concentration in arctic mixed-phase stratus clouds dur- ing ISDAC and M-PACE, J. Geophys. Res., 117, D15207, doi:10.1029/2012JD017668, 2012.

Jacob, D. J., Crawford, J. H., Maring, H., Clarke, A. D., Dibb, J. E., Emmons, L. K., Ferrare, R. A., Hostetler, C. A., Russell, P. B., Singh, H. B., Thompson, A. M., Shaw, G. E., McCauley, E., Pederson, J. R., and Fisher, J. A.: The Arctic Research of the Composition of the Troposphere from Aircraft and Satellites (ARCTAS) mission: design, execution, and first results, Atmos. Chem. Phys., 10, 5191-5212, doi:10.5194/acp-10-5191-2010, 2010.

Jensen, E. J., Lawson, P., Baker, B., Pilson, B., Mo, Q., Heymsfield, A. J., Bansemer, A., Bui, T. P., McGill, M., Hlavka, D., Heymsfield, G., Platnick, S., Arnold, G. T., and Tanelli, S.: On the importance of small ice crystals in tropical anvil cirrus, Atmos. Chem. Phys., 9, 5519-5537, doi:10.5194/acp-9-5519-2009, 2009.

Kay, J. E., L'Ecuyer, T., Gettelman, A., Stephens, G., and O’Dell, C.: The contribution of cloud and radiation anomalies to the 2007 Arctic sea ice extent minimum, Geophys. Res. Lett. , 35, L08503, doi:10.1029/2008GL033451, 2008.

Korolev, A. V.: Reconstruction of the Sizes of Spherical Particles from Their Shadow Images. Part I: Theoretical Considerations., J. Atmos. Oceanic Technol., 24, 376-389, 2007.

Korolev, A. V. and Field, P. R.: The Effect of Dynamics on MixedPhase Clouds: Theoretical Considerations, J. Atmos. Sci., 65, 66-86, 2008.

Korolev, A. V., Emery, E. F., Strapp, J. W., Cober, S. G., Isaac, G. A., Wasey, M., and Marcotte, D.: Small ice particles in tropospheric clouds: fact or artifact? Airborne Icing Instrumentation Evaluation Experiment, Bull. Amer. Meteor. Soc., 92, 967-973, 2011.

Korolev, A. V., Emergy, E., and Creelman, K.: Modification and Tests of Particle Probe Tips to Mitigate Effects of Ice Shattering, J. Atmos. Oceanic Technol., 30, 690-708, 2013.

Lance, S., Brock, C. A., Rogers, D., and Gordon, J. A.: Water droplet calibration of the Cloud Droplet Probe (CDP) and inflight performance in liquid, ice and mixed-phase clouds during ARCPAC, Atmos. Meas. Tech., 3, 1683-1706, doi:10.5194/amt3-1683-2010, 2010.

Larson, V. E., Kotenberg, K. E., and Wood, N. B.: An analytic longwave radiation formula for liquid layer clouds, Mon. Weather Rev., 135, 689-699, 2007.

Lathem, T. L., Beyersdorf, A. J., Thornhill, K. L., Winstead, E. L., Cubison, M. J., Hecobian, A., Jimenez, J. L., Weber, R. J., Anderson, B. E., and Nenes, A.: Analysis of CCN activity of Arctic aerosol and Canadian biomass burning during summer 2008, Atmos. Chem. Phys., 13, 2735-2756, doi:10.5194/acp-13-27352013, 2013.

Lawson, R. P., Baker, B. A., and Schmitt, C. G.: An overview of microphysical properties of Arctic clouds observed in May and July 1998 during FIRE ACE, J. Geophys. Res., 106, 14989-15014, 2001.

Lemke, P., Ren, J., Alley, R. B., Allison, I., Carrasco, J., Flato, G., Fujii, Y., Kaser, G., Mote, P., Thomas, R. H., and Zhang, T.: Observations: changes in Snow, Ice and Frozen Ground, in: Climate Change 2007: The Physical Science Basis. Contribution of Working Group I to the Fourth Assessment Report of the Intergovernmental Panel on Climate Change, edited by: Solomon, S., Qin, D., Manning, M., Chen, Z., Marquis, M., Averyt, K. B., Tig- 
nor, M., and Miller, H. L., Cambridge University Press, Cambridge, UK and New York, NY, USA, 337-383, 2007.

Lihavainen, H., Kerminen, V.-M., and Remer, L. A.: Aerosol-cloud interaction determined by both in situ and satellite data over a northern high-latitude site, Atmos. Chem. Phys., 10, 1098710995, doi:10.5194/acp-10-10987-2010, 2010.

McFarquhar, G. M., Zhang, G., Poellot, M. R., Kok, G. L., McCoy, R., Tooman, T., Fridlind, A., and Heymsfield, A. J.: Ice properties of single-layer stratocumulus during the MixedPhase Arctic Cloud Experiment, J. Geophys. Res., 112, D24201, doi:10.1029/2007JD008633, 2007.

McFarquhar, G. M., Ghan, S., Verlinde, J., Korolev, A., Strapp, W., Schmid, B., Tomlinson, J. M., Wolde, M., Brooks, S. D.,Cziczo, D., Dubey, M. K., Fan, J., Flynn, C., Gultepe, I., Hubbe, J., Gilles, M. K., Laskin, A., Lawson, P., Leaitch, W. R., Liu, P., Liu, X., Lubin, Dan., Mazzoleni, C., MacDonald, A.-M., Moffet, R. C., Morrison, H., Ovchinnikov, M., Shupe, M. D., Turener, D. D., Shaocheng, X., Zelenyuk, A., Bae, K., Freer, M., and Glen, A.: Indirect and Semi-Direct Aerosol Campaign, Bull. Amer. Meteor. Soc., 92, 183-201, 2011.

Mellado, J. P.: The evaporatively driven cloud-top mixing layer, J. Fluid Mech., 660, 5-36, 2010.

Morrison, H., Pinto, J. O., Curry, J. A., and McFarquhar, G. M.: Sensitivity of modelled arctic mixed-phase stratocumulus to cloud condensation and ice nuclei over regionally varying surface conditions, J. Geophys. Res., 113, D05203, doi:10.1029/2007JD008729, 2008.

Palm, S. P., Strey, S. T., Spinhirne, J., and Markus, T.: Influence of Arctic sea ice extent on polar cloud fraction and vertical structure and implications for regional climate, J. Geophys. Res., 115, D21209, doi:10.1029/2010JD013900, 2010.

Perovich, D. K., Andreas, E. L., Curry, J. A., Eiken, H., Fairall, C. W., Grenfell, T. C., Guest, P. S., Intrieri, J., Kadki, D., Lindsay, R. W., McPhee, M. G., Morison, J., Moritz, R. E., Paulson, C. A., Pegau, W. S., Persson, P. O. G., Pinkel, R., Richter-Menge, J. A., Stanton, T., Stern, H., Sturm, M., Tucker, W. B., and Uttal, T.: Year in Ice Gives Climate Insights, EOS, 80, 481-492, 2000.

Perovich, D. K., Richter-Menge, J. A., Jones, K. F., and Light, B.: Sunlight, water, and ice: extreme Arctic sea ice melt during the summer of 2007, Geophys. Res. Lett., 35, L11501, doi:10.1029/2008GL034007, 2008.

Pettersen, S.: On the causes and the forecasting of the California fog. Bull. Amer. Meteor. Soc. 19, 49-55, 1938.

Platnick, S.: Vertical photon transport in cloud remote sensing problems, J. Geophys. Res., 105, 22919-22935, 2000.

Pruppacher, H. R. and Klett, J. D.: Microphysics of Clouds and Precipitation, Springer Dordrecht Heidelberg London New York, 954 pp., 2010.
Schlenczek, O., Fugal, J. P., Bower, K. N., Crosier, J., Flynn, M. J., Lloyd, G., and Borrmann, S.: Properties of pure ice clouds in an alpine environment, Extended abstract, Amer. Meteor. Soc. 14th Conference on Cloud Physics, 07-11 July, Boston, USA, 2014.

Schweiger, A. J. and Lindsay, R. W.: Relationships between Arctic Sea Ice and Clouds during Autumn, J. Climate, 21, 4799-4810, 2008.

Shupe, M. D. and Intieri, J. M.: Cloud radiative forcing of the Arctic surface: The influence of cloud properties, surface albedo, and solar angle, J. Climate, 17, 616-628, 2004.

Siems, S. T. and Bretherton C. S. : A numerical investigation of cloud-top entrainment instability and related experiments, Q. J. Roy. Meteor. Soc., 118, 787-818, 1992.

Spuler, S. M. and Fugal, J.: Design of an in-line, digital holographic imaging system for airborne measurement of clouds, Appl. Opt., 50, 1405-1412, 2011.

Stevens, B.: Atmospheric Moist Convection, Annu. Rev. Earth Planet. Sci., 33, 605-643, 2005.

Stevens, B., Moeng, C.-H., Ackerman, A. S., Bretherton, C. S., Chlond, A., de Roode, S., Edwards, J., Golaz, J.-C., Jiang, H., Khairoutdinov, M., Kirkpatrick, M. P., Lewellen, D. C., Lock, A., Müller, F., Stevens, D. E., Whelan, E., and Zhu, P.: Evaluation of Large-Eddy Simulations via Observations of Nocturnal Marine Stratocumulus, Mon. Weather Rev., 133, 1443-1462, 2005.

Struthers, H., Ekman, A. M. L., Glantz, P., Iversen, T., Kirkevåg, A., Mårtensson, E. M., Seland, Ø., and Nilsson, E. D.: The effect of sea ice loss on sea salt aerosol concentrations and the radiative balance in the Arctic, Atmos. Chem. Phys., 11, 3459-3477, doi:10.5194/acp-11-3459-2011, 2011.

Verlinde, J., Herrington, Y., McFarquhar, G. M., Yannuzzi, V. T., Avramov, A., Greenberg, S., Johnson, N., Zhang, G., Poellot, M. R., Mather, J. H., Turner, D. D., Eloranta, E. W., Zak, B. D., Prenni, A. J., Daniel, J. S., Kok, G. L., Tobin, D. C., Holz, R., Sassen, K., Spangenberg, D., Minnis, P., Tooman, T. P., Ivey, M. D., Richardson, S. J., Bahrmann, C. P., Shupe, M., DeMott, P. J., Heymsfield, A. J., and Schofield, R.: The Mixed-Phase Arctic Cloud Experiment, Bull. Amer. Meteor. Soc, 88, 205-221, 2007.

Wendisch, M. and Brenquier, J.-L.: Airborne Measurements for Environmental Research: Methods and Instruments, Wiley-VCH Verlag GmbH \& Co. KGaA, Weinheim, Germany, 655 pp., 2013.

Wendisch, M., Yang, P., and Ehrlich, A.: Amplified climate changes in the Arctic: Role of clouds and atmospheric radiation. Sitzungsberichte der Sächsischen Akademie der Wissenschaften zu Leipzig. Mathematisch-Naturwissenschaftliche Klasse, S. Hirzel Verlag, Stuttgart/Leipzig, 132, 1-34, 2013. 